\title{
The Lack of Subjective Experience in Hybrid Intelligent Agents in Interactive Storytelling
}

\author{
Olivier Guy and Ronan Champagnat \\ Université La Rochelle/L3i \\ Pôle Science et Technologie \\ 17042 La Rochelle, France \\ olsat@yahoo.com, ronan.champagnat@univ-lr.fr
}

\begin{abstract}
We need a model for non-player characters (NPCs) in interactive storytelling, and recent advances in neurocognitive science have not brought to a close the controversies of the subjective and objective experience being both verses of the same coin. The NPCs are still made desperately from a 'third party' point $\mathrm{f}$ view, the exact opposite of the subjective experience, while we want to show that this method only produces weaker user experience. This is a hard problem, described by David Chalmers in the philosophy of the mind: we know what it is to be ourselves, we know what the outside world looks like from our point of view, but we have no idea what it is to be something, or even more difficult, someone else. Our goal as in Crawford is to reach the meaningful interaction with the NPC and we want to prove that this may not be attained through third party cognitive models. As a prospective we invite the developers to work on psychodynamic psychology. Moreover, French psychodynamics are a valuable intercultural tool spread in the entire Latin world and can be powerful to describe, heal, and treat human features, while Fodor's followers have exclusive theoretical access to our game models. It is a good way to introduce diversity in our community.
\end{abstract}

\section{$1 \quad$ Introduction}

This work takes place among the dialectics of subjective experience, by opposition to the objective experience reflected mostly in the field of the philosophy of the mind. There is a major gap in the description of the mind with on the one hand the experience of the subject and the other hand what is described by a third party - the objective experience. These problems have been brought to light by papers such as 'What is it like to be a bat?' by Thomas Nagel, [Nagel 1974] which explains no matter how deep we might know how the brain and perceptual system of bat works, we have no idea what it is to be one - hence the title. We may have many different models and we will speak in-depth of a few of them later- for the human agent, we lack the subjective side of the problem.

The notion of pre-reflective self-consciousness is related to the idea that experiences have a subjective 'feel' to them, a certain -phenomenal- quality of 'what it is like' or what it 'feels' like to have them. As it is usually expressed outside of 
phenomenological texts, to undergo a conscious experience necessarily means that there is something it is like for the subject to have that experience [Searle 1992].

Our goal is to show that our current working models are all inspired with objective psychology: cognitive, neuroscience, or behaviorism. We would like to prove that we need more subjective experience-side psychology in our models. The reason for such a problem is that subjective experience as described by Chalmers is very complicated. Moreover, it has been best described by Lacan in France, who has the reputation for being impossible to be translated in English. In the end our models, and we will show examples, are disappointing. As a prospective we would like to incite IT specialists to reflect on this major problem of objective/subjective dichotomy in the design of the characters.

In this paper we will follow the topology of Espen Aarseth in that we are willing to build a theoretical model that is capable of making a mimetic world, by opposition to arbitrary, which does not seem to be a concern in Katherine Isbisker. It may seem superfluous to specify this point, but in psychology, the closer we will want to be to the truth of the human psyche and the more it will make a difference. In the case of a deterministic game, our study will target the simulation of the relationship between the storyteller and the user, while, in the case of a non-deterministic application we would be in the context of providing a model for a verbose agent that would tell a story in natural language [Aarseth, et al., 2003]. Our niche is between the logic of cognitive science which believes in some objectivity of thought as matter of research, and social psychology, the scientific study of how people's thoughts, feelings, and behaviors are influenced by the actual, imagined, or implied presence of others, studied empirically, but by a third party.

The works of Stephane Donikian (Donikian, 2004) exposed the even growing antagonism of the approaches in the field of cognitive science and the substantial lack of federative models to propose an architecture allowing to connect together the various functions used in the human behavior even for the simplest ones. Reproducing the human behavior takes the developing of formalisms to model. We also need systems to simulate autonomous anthropomorphic characters. We do not have any theory for determining either the necessary or sufficient structures needed to support their particular capabilities. It is a basic tenet of cognitive sciences in the so called identification problem that choosing the one out of several candidate models that best describes a given set of results, is unsolvable in principle (Fum, Missier, \& Stocco, 2007) (Anderson, 1976)

In this context we try to point out a matter that is on the border of three different subjects, philosophy of the mind, mind models, and neurocognitive science. Our premise is that subjective experience is absent of the current models for interactive storytelling. We would like to go further and tell how interactive media could be profitable to the models of subjective experience, mostly psychoanalysis.

We will try to prove that everything that we try to simulate in a storytelling, can boil down to a table-top RPG ${ }^{1}$, [Delmas, Champagnat, Augeraud 2009] hence can boil down to a psychodynamic perspective, i.e. a story being told from a game master,

\footnotetext{
${ }^{1}$ Role playing game.
} 
who has all the $\mathrm{NPCs}^{2}$ in its power, [Velsen, Josh, Gustav 2009] to a user who receives the story.

- We will try to tell the difference between subjective experience and objective experience.

- We have then tried to show possible gaps within the state of the art.

\section{Distinctions between Objective Point of View and Subjective Experience}

The distinction with subjective experience is the one that is made by Chalmers, the famous philosopher of the mind (Chalmers, 1996), when he speaks of a 'whir of information processing'- e.g. a whir of information processing happens when it comes to solve the problem of subjective experience, while there are, according to him, easy problems. It is obviously not as simple as the one as put by Donikian in the objective point of view. Chalmers says that reacting to environmental stimuli is an 'easy problem', although no expert would qualify such a problem of easy, the model can be easily put into words. By comparison with the 'hard problem of subjective experience', we could probably be calling it easy. Telling a story is a subjective experience matter because it requires psychodynamic interaction, should it be synchronous or asynchronous - a story can be received in the meantime it is told or not.

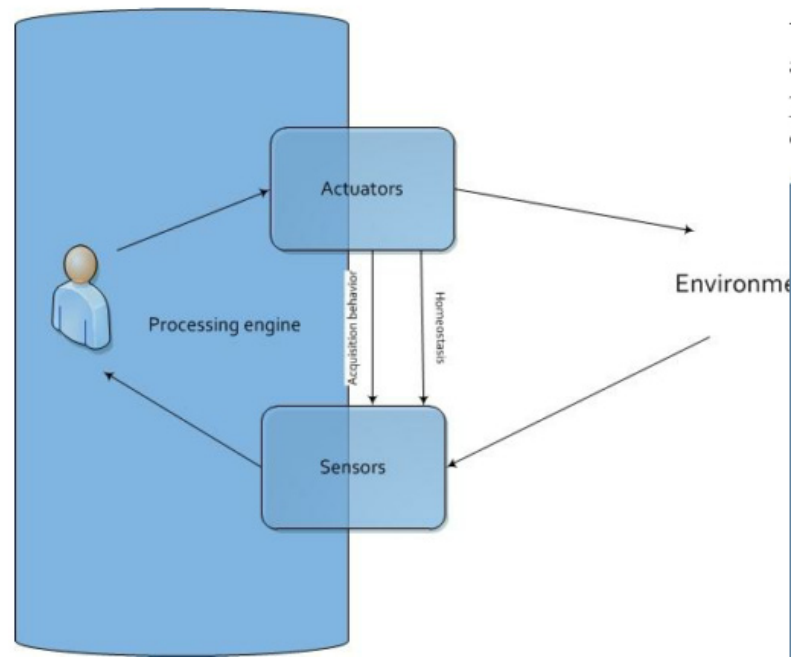

Fig. 1. The representation of the anthropoid agent in Donikian as in Von Uexküll (Uexküll, 1956)

${ }^{2}$ Non-player character. 
When we speak of storytelling, we imply that 'Style is the man' (Lacan J., 1966) as used to say Jacques Lacan. The enunciation of the story and its style contain more than just the behavior of the man with its environment. It contains a part of its psyche. The social decryptions by Roland Barthes of a number of habits such as the way of dressing connote the intimate of the subject. Thus there is a semiology of the appearances, which bears value of the vision of the world that the individual has of herself and of her environment. Then telling a story boils down to a psychodynamic interaction between two people more accurately than just between her and her environment.
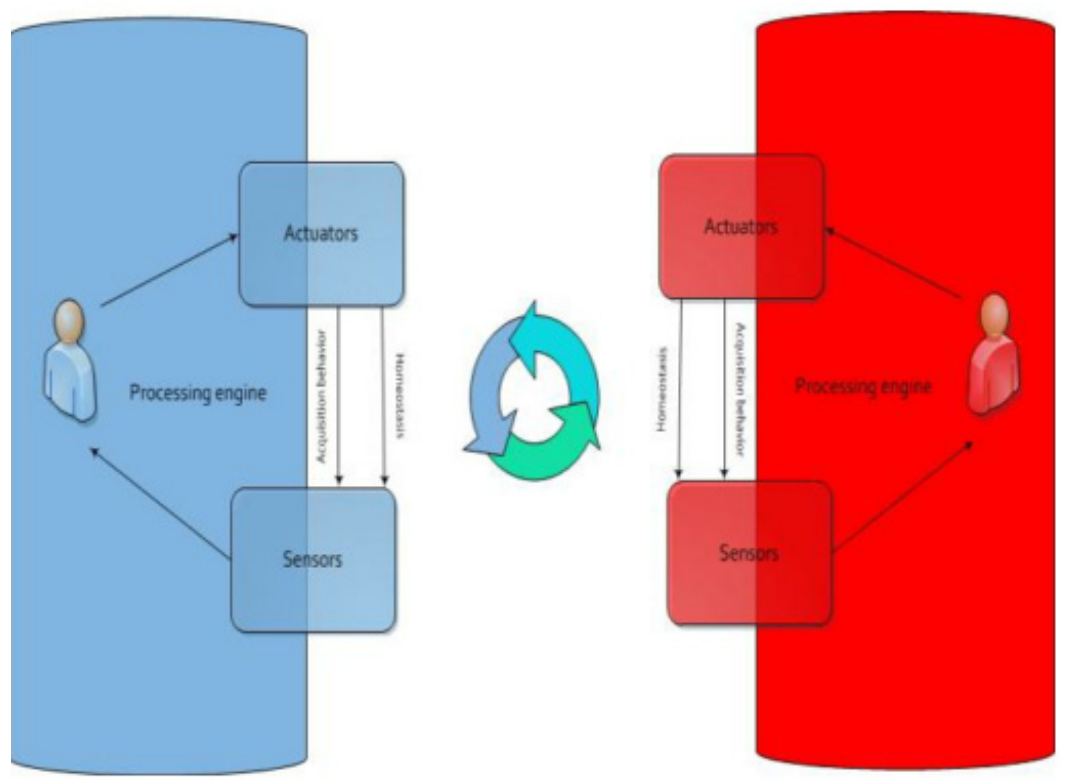

Fig. 2. In our views, the mind of the storyteller - should it be an emergent agent or not, through his NPCs; meets the psyche of the user

Still according to Donikian the goal of our work as designers of characters is to make them look credible or 'natural-looking' so to say. To that purpose we would have a multiple layer of a cognitive architecture that would fit a classic cognitive doctrine that would be in accordance with Fodor or Pylyshyn. Mind that the natural isomorphism of the cognitivism is not agreed obviously, and that Edelman, Reeke, and the psychoanalysts showed different aspects of the problem, this is what we will try to show here.

Then an idea could be of considering the matter of storytelling as a relationship between two individuals with transference, mechanisms of defense, fantasies, and desires. A storytelling tells as much on a literal level of understanding, than it tells about the storyteller, according to Paul Ricoeur of whose works are based on the relationships between the two times of the narrative, the one of the life, and the one of the affective action. 
More than anything: the relationship of the human being to another is a 'narrative identity'. It means that we build our identity out of the story that we tell of ourselves or through the stories that we tell to other by ourselves. Hence our question: why try to make a character, world, story, look natural out of scratch by the machine, while storytelling results of an interaction - the story being told from a human to another?.

\section{A Short Comparative Analysis of the Iago Character}

\subsection{Gaps in the Current Models}

On the prospective side if we are inclined to develop 'rich characters', meaning 'qualitative characters', we could probably argue that a few parameters are completely off the picture in the current models:

- Natural language;

- Poetry;

- Depth;

- Diversity in the characterization of the NPCs...

Nicolas Szilas states (Szilas, 2010) that irrational behaviors so far are not taken into account in the industry. At a general level, Marie-Laure Ryan provides an example of a linear negative case (Ryan, 2001) She takes the example of a classical tragedy Anna Karenina, and observes that if the user were to play Anna Karenina, he would not want to behave the way she behaves and finally cause the death of his character. There's a considerable discrepancy between being in someone's skin and being separated by an interface, manipulating a character. Pure tragedy, while consisting a perfect example of linear narrative, does not fit with the interactive context, because the user would not want to be more or less forced to go into such a tragic solution.'

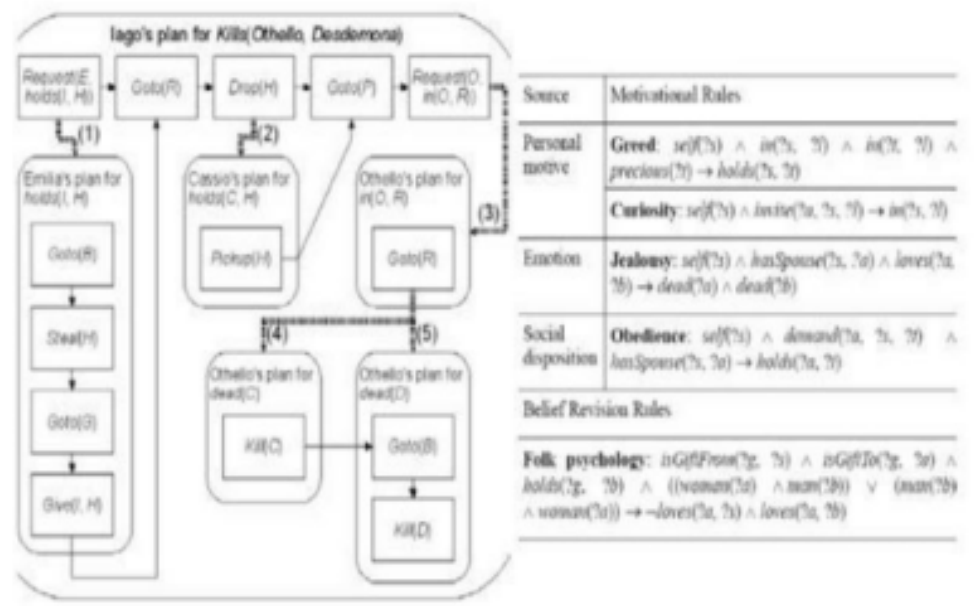

Fig. 3. A behavioral model for Iago's plan for Othello to kill Desdemona in Othello (Chang \& Soo, 2008) 
We may infer two reasons: the first is that no NPC is designed to be a tragic character. As tragic as the game scenario may be, and after thinking our characters as logical and rational machines for decades, the gamer could not think the same meaningfulness in his characters as the designers if the latter figured tragic ones. This would be a brand new way of playing, for a new line of games, and a new generation of players: tragedy is not fun; games so far are to be fun. In the end we know that a behavior that could be closer to poetry than to rationality poses a lot of problems in terms of simulations. Psychoanalysis takes into account those behaviors.

As a matter of fact the character is much more subtle as the following lines reveals:

'Now, I do love her too;

Not out of absolute lust, though, peradventure,

I stand accountant for as great a sin,

But partly led to diet my revenge,

For that I do suspect the lusty Moor

Hath leap'd into my seat: the thought whereof

Doth, like a poisonous mineral, gnaw my inwards;

And nothing can or shall content my soul

Till I am even'd with him, wife for wife;

Or, failing so, yet that I put the Moor

At least into a jealousy so strong

That judgment cannot cure. He also says: I'll have our Michael Cassio on the hip,

Abuse him to the Moor in the rank garb... '

(Shakespeare, 2012)

'Iago is the acid which comes from our failed narcissistic relationships; it slowly eats into our object articulations, even the most honestly loving. This corrosive and underhand action of the deathwish drive seems even more vowed to be efficient that Othello, deep in himself does not have a character built only on idealized and toned down tenderness, without any other constituent: his Moorish blood reminds the heredity of the id that froths beneath the surface of his 'noble' apparent behavior.' (Bergeret, 2003).

What Jean Bergeret tries to show through this analysis is what can be universal in Iago. The reader may appreciate the poetics of the prose in which he describes the char acter, even though it is only a translation from the French. We can see that from the rough work of BDI to the non-interactive piece of Shakespeare there is a huge discrepancy. The first question is: what if he was to act in an interactive environment, how would he behave? The second question could be: do we have enough analysis, poetics or depth, to simulate him, to have a convincing Iago in the sense of our state of the art with either (Bergeret, 2003) or (Chang \& Soo, 2008)?.

As we may see, this excerpt is pure subjective experience from the character of Iago, though it is harder to see where the diagram is going, probably because it tries to rationalize 'a whirl of information', into a very terse formula. Indeed, psychoanalysis is more verbose, but we cannot be ambitious in our narratives while trying to avoid the use of natural language. It seems on the one hand that some psychologist/philosophers 
believe that they can bridge the gap between the subjective experience and the logic of machinery.

'Subjective psychological phenomena are the legitimate concern of psychologists, but these must not be confused with thoughts and their laws which, given their objectivity and concern with truth, are the proper subject matter for logicians. Logic is set apart because it alone is charged with 'the task of discovering the laws of truth, not the laws of taking things to be true or of thinking'. [Hutto 2003] Thoughts are therefore implicitly within the grasp of logic, thus within the grasp of computers. While Lacan says that the truth of the thoughts is not even within the grasp of the subject who produces them... This is one of the rules of poetry. Those schools of thought are very significant of the intellectual severance between the Latin world and the - dominant- English speaking world.

\section{Lacanian Concepts Which Could Be of Use to Design a NPC}

We offer quadrangular characters to the acumen of the designer instead of the classic Fodorism. They are prompted by, as subjects, desire, mesmerized by The Thing Das Ding in German, which Lacan derived from Kant- trying to get a kick - for lack of a better expression- until they are put on the path of self-destruction, and organized by the symbolic law. These concepts are part of the human experience, we are persuaded of it, thus they lack in our models so far.

\subsection{The Thing}

We could say of the Thing that it magnetizes the desire. Every object of desire is under some aspect a delusion. We only imagine that we desire such or such object. In reality, the desire, through the objects it seems to expect, only looks for one thing: the Thing, of which it will never have any representation, which is not a goal since it cannot be reached, but around which the desire never ceases to revolve. So far we have been able to make characters that want to stuff themselves on experience points or gold coins, but this concept helps us understand something no so logical with hu man psyche: what's the point of being rich and powerful up to a certain point? And more than this, why are we trying to reach a point beyond the one we thought we originally wanted to go?.

- The young woman who enters medical school thinking that she will help old people while unconsciously she wants to please her dad;

- The man who becomes a priest and paints because he has unsolved desires with his mom;

- The man who turns to angry politics because he had absent parents and wants to fill a gap...

This brings us to the second concept, enjoyment: the use and abuse of pleasures until there are put on the path of self-destruction. 


\subsection{Enjoyment}

The principle of pleasure explained by Freud is the principle of limitation of pleas ure, since it imposes to get a kick out of life as little as possible. But at the same time as he seeks pleasure while limiting it, the subject strives, constantly, to overcome the limits of the pleasure principle. Getting a kick is that uncomfortable position that hurts and is pleasant at the same time... For lack of a better translation for jouissance we chose to use this way of saying it: having a pleasure that hurts a little at the same time, such as having sex, or watching people fight.

It does not mean that the attempt for the maximization of the pleasure results in the coming of more pleasure. There's a degree of pleasure that the subject cannot tolerate that Lacan calls jouissance in the seminaire VII and that we could call an abuse of pleasure. The deathwish is the constant desire to overcome the principle of pleasure and to reunite with The Thing and to get more kick out it. In this sense, getting a kick is a path to death - seminaire XVII.

Why did Iago act like that then? Yes, he did break it all, but what a kick must it have been to watch everything fall apart.

We could find examples in rich and good looking people who waste their lives before 30 with sex, drugs, and parties...

\subsection{The Law and the Other}

The desire takes us towards The Thing is the reverse of the law. The Other - with a big O- designates what the subject depends upon, the place of its determinations, and also what is required to put order in the human world in the subject, i.e. the place of the law. It is an organizing instance, not a repressive one.

We want to leave to the imagination of the developer the leeway of using these concepts which are among the most powerful to describe the human psyche in $\mathrm{La}$ can's theory. There are obviously many others, but the first step is to take into consideration the existence of the unconscious, which is completely left behind by the other models. In our model we have, at least more depth than just:' NPC wants money because money is useful, NPC locates money, and NPC takes money'.

\section{Conclusion}

Psychoanalytical models can be as efficient as neurocognitive ones, but not of the same sort. Psychoanalysis is much more on the side of history, of the humanities, than on the life sciences. No one has ever asked an historian, a sociologist, an economist, a controlled experimental check of his results. Why then when we assume that story telling is closer to psychoanalysis than cognitive science should we have the judgment filter? This is not the same order of things, as Blaise Pascal might have said. There are different kinds of science in which the criteria of observation and verification are not identical. Psychoanalysis and neuroscience seem to involve logically each other, in a parallel way lately. 
Every one of which could claim to be true, while the other may or may not be true or false. Each side of the coin can coexist with the other, joined and separated at the same time, and the other could be intact or erased. Obviously, today, subjective experience and objective experience are both sides of the same coin. The storytellers and characters as automatons is a mistake that we should avoid in order not to repeat the same imbalance that exists within the design of computer apps in general humanities are underrepresented in computer development.

The dichotomy made by Chalmers in the easy and hard problems of the mind is useful in the sense that so far our models are practical but tries to solve what he calls easy problems such as perception, navigation in complex environments, path planning, memory but they tend to be very far in a qualitative way from anything that we need to solve the complicated problems posed by the poetics of IS.

\section{References}

1. Aarseth, E., Smedstad, S.M., Sunnanâ, L.: A MULTI-DIMENSIONAL TYPOLOGY OF GAMES. Utrecht, s.n (2003)

2. Bergeret, J.: Lapersonnalite normale etpathologique. D unod, Paris (2003)

3. Cavazza, M., Pizzi, D.: International conference on entertainment. In: TID SE (2006)

4. Cavazza, M., Pizzi, D.: University of Teeside (2012), http: / /wwwscm.tees.ac.uk/f . charles/bovary.php (retrieved May 21, 2012)

5. Cavazza, M., Pizzi, D.: Merchant of Venice. University of Teeside: http: / /www-scm.tees.ac.uk/f.charles/merchant-of-venice.php (retrieved May 21, 2012)

6. Chalmers, D.: The Conscious Mind. In: Search of a Fundamental Theory, Oxford University Press, Oxford (1996)

7. Chang, H.M., Soo, V.W.: International Conference on Intelligent Technologies for Interactive Entertainment (2008)

8. Crawford, C.: Artists and engineers as cats and dogs: implications for interactive storytelling. Computer graphics (2002)

9. Delmas, G., Champagnat, R., Augeraud, M.: From tabletop RPG to interactive storytelling: Definition of a story manager for videogames. In: Iurgel, I.A., Zagalo, N., Petta, P. (eds.) ICIDS 2009. LNCS, vol. 5915, pp. 121-126. Springer, Heidelberg (2009)

10. Donikian, S.: Modélisation, contrôle et animation d'agents virtuels autonomes évoluant dans des environnements informés et structurés. HDR IFSIC, Rennes (2004)

11. Fodor, J.: The modularity ofthe mind. Cambridge University Press, Cambridge (1983)

12. Hutto, D.: Wittgenstein and the end of philosophy. Palgrave Macmillan, New York (2003)

13. Lacan, J.: Le séminaire sur l'Identification IX. le seuil, Paris (1962)

14. Lacan, J.: Le seminaire VII. Le seuil, Paris (1986)

15. Lacan, J.: Seminaire VII. Seuil, Paris (2006)

16. Lacan, J.: Seminaire XI Quatre concepts fondamentaux de la psychanalyse. Le seuil, Paris (1973)

17. Lacan, J.: Seminaire XVII. Seuil, Paris (2006)

18. Lacan, J.: Les complexes familiaux dans la formation de l'individu, Paris (1966)

19. Lacan, J.: Les complexes familiaux dans la formation de l'individu. Navarrin, Paris (1966)

20. Nagel, T.: What is it like to be a bat? In: The Philosophical Review (1974) 
21. Peinado, F., Cavazza, M., Pizzi, D.: Revisiting character-based affective storytelling under a narrative BDI framework. In: Spierling, U., Szilas, N. (eds.) ICIDS 2008. LNCS, vol. 5334, pp. 83-88. Springer, Heidelberg (2008)

22. Racamier. L'inceste et l'incestuel. College de Psychanalyse, Paris (1995)

23. Ryan, M.-L.: Beyond Myth and Metaphor - The Case of Narrative in Digital Media. The International Journal of Computer Game Research (2001)

24. Searle, J.R.: The Rediscovery of the Mind. MIT press, Cambridge (1992)

25. Staller, Sloman, \& Ben-Zeev, Perspective effects in nondeontic versions of the Wason selection task. Memory \& Cognition (2001)

26. Szilas (2010) Requirements for Computational Models of Interactive Narrative. In: AAAI (2010)

27. van Velsen, M., Williams, J., Verhulsdonck, G.: Table-Top Gaming Narratology for Digital Interactive Storytelling. In: Iurgel, I.A., Zagalo, N., Petta, P. (eds.) ICIDS 2009. LNCS, vol. 5915, pp. 109-120. Springer, Heidelberg (2009) 